\title{
Polar wolf optimization algorithm for solving optimal reactive power problem
}

\author{
Kanagasabai Lenin \\ Department of Electrical and Electronics Engineering, Prasad V. Potluri Siddhartha Institute of Technology, India
}

\begin{tabular}{l} 
Article Info \\
\hline Article history: \\
Received Jul 19, 2019 \\
Revised Feb 19, 2020 \\
Accepted Mar 3, 2020 \\
\hline
\end{tabular}

Keywords:

Polar wolf

Reactive power

Transmission loss

\begin{abstract}
This paper proposes polar wolf optimization (PWO) algorithm to solve the optimal reactive power problem. Proposed algorithm enthused from actions of polar wolves. Leader's wolves which denoted as $\mathrm{x}_{\alpha}$ are accountable for taking judgment on hunting, resting place, time to awaken etc. second level is $x_{\beta}$ those acts when there is need of substitute in first case. Then $x_{\gamma}$ be as final level of the wolves. In the modeling social hierarchy is developed to discover the most excellent solutions acquired so far. Then the encircling method is used to describe circle-shaped vicinity around every candidate solutions. In order to agents work in a binary space, the position modernized accordingly. Proposed PWO algorithm has been tested in standard IEEE 14, 30, 57, 118, 300 bus test systems and simulation results show the projected algorithms reduced the real power loss considerably.
\end{abstract}

This is an open access article under the $\underline{C C B Y-S A}$ license.

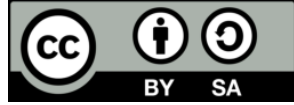

\section{Corresponding Author:}

Kanagasabai Lenin,

Department of Electrical and Electronics Engineering,

Prasad V. Potluri Siddhartha Institute of Technology,

Kanuru, Vijayawada, Andhra Pradesh -520007, India.

Email: gklenin@gmail.com

\section{INTRODUCTION}

Reactive power problem plays an important role in secure and economic operations of power system. Numerous types of methods [1-6] have been utilized to solve the optimal reactive power problem. However many scientific difficulties are found while solving problem due to an assortment of constraints. Evolutionary techniques [7-16] are applied to solve the reactive power problem. This paper proposes polar wolf optimization (PWO) algorithm to solve the optimal reactive power problem. PWO enthused from actions of polar wolves. In the modeling social hierarchy is developed to discover the most excellent solutions acquired so far.

Then the encircling method is used to describe circle-shaped vicinity around every candidate solutions. The hunting technique assists candidate solutions to trace the prey [17]. Leaders of a pack are defined as Alpha and it makes all vital decisions in the group about day to day activity. Alpha will be supported by Beta in all aspects and particularly performing actions. Delta executes its duty as scouts, guard, concierge. Exploration and exploitation are balanced in iterations. Modernizing mechanism of wolves is function of three vectors position; $\mathrm{X}_{1}, \mathrm{X}_{2}, \mathrm{X}_{3}$ which endorse every wolf to reach three most excellent solutions. For that the agents will work in a binary space. Proposed PWO algorithm has been tested in standard IEEE 14, 30, 57, 118, 300 bus test systems and simulation results shows that active power loss has been reduced. 


\section{PROBLEM FORMULATION}

Objective of the problem is to reduce the true power loss:

$$
\mathrm{F}=\mathrm{P}_{\mathrm{L}}=\sum_{\mathrm{k} \in \mathrm{Nbr}} \mathrm{g}_{\mathrm{k}}\left(\mathrm{V}_{\mathrm{i}}^{2}+\mathrm{V}_{\mathrm{j}}^{2}-2 \mathrm{~V}_{\mathrm{i}} \mathrm{V}_{\mathrm{j}} \cos \theta_{\mathrm{ij}}\right)
$$

Voltage deviation given as follows:

$$
\mathrm{F}=\mathrm{P}_{\mathrm{L}}+\omega_{\mathrm{v}} \times \text { Voltage Deviation }
$$

Voltage deviation given by:

$$
\text { Voltage Deviation }=\sum_{i=1}^{N p q}\left|V_{i}-1\right|
$$

Constraint (equality)

$$
\mathrm{P}_{\mathrm{G}}=\mathrm{P}_{\mathrm{D}}+\mathrm{P}_{\mathrm{L}}
$$

Constraints (inequality)

$$
\begin{aligned}
& \mathrm{P}_{\text {gslack }}^{\min } \leq \mathrm{P}_{\text {gslack }} \leq \mathrm{P}_{\text {gslack }}^{\text {max }} \\
& \mathrm{Q}_{\mathrm{gi}}^{\min } \leq \mathrm{Q}_{\mathrm{gi}} \leq \mathrm{Q}_{\mathrm{gi}}^{\max }, \mathrm{i} \in \mathrm{N}_{\mathrm{g}} \\
& \mathrm{V}_{\mathrm{i}}^{\min } \leq \mathrm{V}_{\mathrm{i}} \leq \mathrm{V}_{\mathrm{i}}^{\mathrm{max}}, \mathrm{i} \in \mathrm{N} \\
& \mathrm{T}_{\mathrm{i}}^{\min } \leq \mathrm{T}_{\mathrm{i}} \leq \mathrm{T}_{\mathrm{i}}^{\max }, \mathrm{i} \in \mathrm{N}_{\mathrm{T}} \\
& \mathrm{Q}_{\mathrm{c}}^{\min } \leq \mathrm{Q}_{\mathrm{c}} \leq \mathrm{Q}_{\mathrm{C}}^{\max }, \mathrm{i} \in \mathrm{N}_{\mathrm{C}}
\end{aligned}
$$

\section{POLAR WOLF OPTIMIZATION}

PWO algorithm enthused from actions of polar wolves. Leader's wolves which denoted as $\mathrm{x}_{\alpha}$ are accountable for taking judgment on hunting, resting place, time to awaken etc. second level is $\mathrm{x}_{\beta}$ those acts when there is need of substitute in first case. Then $\mathrm{x}_{\gamma}$ be as final level of the wolves. In the modeling social hierarchy is developed to discover the most excellent solutions acquired so far. Then the encircling method is used to describe circle-shaped vicinity around every candidate solutions. The hunting technique assists candidate solutions to trace the prey. Exploration and exploitation are balanced in each iteration. Modernizing mechanism of wolves is function of three vectors position $-X_{1}, X_{2}, X_{3}$ which endorse every wolf to reach three most excellent solutions. For that the agents will work in a binary space.

$$
\begin{aligned}
& \bar{D}=\left|\bar{C} \bar{X}_{p}(t)-\bar{X}(t)\right| \\
& \bar{X}(t+1)=\bar{X}_{p}(t)-\vec{A} \cdot \vec{D} \\
& \vec{A}=2 \vec{a} \cdot \overrightarrow{r_{1}}-\vec{a} \\
& \vec{C}=2 \cdot \overrightarrow{r_{2}} \\
& \vec{a}=2-t * \frac{2}{m_{i} \text { iteration }}
\end{aligned}
$$

The state of wolves are adjusted by,

$$
\begin{aligned}
& \overrightarrow{D_{\alpha}}=\left|\overrightarrow{C_{1}}, \overrightarrow{X_{\alpha}}-\vec{X}\right| \\
& \overrightarrow{D_{\beta}}=\left|\overrightarrow{C_{2}}, \overrightarrow{X_{\beta}}-\vec{X}\right|
\end{aligned}
$$




$$
\overrightarrow{D_{\gamma}}=\left|\overrightarrow{C_{3}}, \overrightarrow{X_{\delta}}-\vec{X}\right|
$$

where $\overrightarrow{X_{\alpha}}, \overrightarrow{X_{\beta}}, \overrightarrow{X_{\gamma}}$ symbolize the locations of $\alpha, \beta, \delta$,

$$
\begin{aligned}
& \overrightarrow{X_{1}}=\overrightarrow{X_{\alpha}}-\overrightarrow{A_{1}} \cdot\left(\overrightarrow{D_{\alpha}}\right) \\
& \overrightarrow{X_{2}}=\overrightarrow{X_{\beta}}-\overrightarrow{A_{2}} \cdot\left(\overrightarrow{D_{\beta}}\right) \\
& \overrightarrow{X_{3}}=\overrightarrow{X_{\beta}}-\overrightarrow{A_{3}} \cdot\left(\overrightarrow{D_{\delta}}\right) \\
& \bar{X}(t+1)=\frac{\overrightarrow{x_{1}+x_{2}+x_{3}}}{3}
\end{aligned}
$$

In order to agents work in a binary space, the position modernizing can be customized by,

$$
\begin{aligned}
& x_{d}^{t+1}=\left\{\begin{array}{c}
1 \text { if sigmoid }\left(\frac{x_{1}+x_{2}+x_{3}}{3}\right) \geq \text { random } \\
0 \text { otherwise }
\end{array}\right. \\
& \text { sigmoid }(a)=\frac{1}{1+e^{-10(x-05)}} \\
& X_{1}, X_{2}, X_{3} \text { are updated by, } \\
& x_{1}^{d}=\left\{\begin{array}{c}
1 \text { if }\left(x_{\alpha}^{d}+\text { bstep }_{\alpha}^{d}\right) \geq 1 \\
0 \text { otherwise }
\end{array}\right. \\
& x_{2}^{d}=\left\{\begin{array}{c}
1 \text { if }\left(x_{\beta}^{d}+\right.\text { bstep } \\
0 \text { otherwise }
\end{array}\right) \geq 1 \\
& x_{3}^{d}=\left\{\begin{array}{c}
1 \text { if }\left(x_{\delta}^{d}+\text { bstep }_{\delta}^{d}\right) \geq 1 \\
0 \text { otherwise }
\end{array}\right.
\end{aligned}
$$

where

$$
\begin{aligned}
& \text { bstep }_{\alpha, \beta, \delta}^{d}=\left\{\begin{array}{c}
1 \text { ifcstep } p_{\alpha, \beta, \delta}^{d} \geq \text { random } \\
0 \text { otherwise }
\end{array}\right. \\
& \operatorname{cstep}_{\alpha, \beta, \delta}^{d}=\frac{1}{1+e^{-10\left(A_{1}^{d} D_{\alpha, \beta, \delta}^{d}-0.5\right)}}
\end{aligned}
$$

Positions and velocities are modernized to improve the performance of the exploration and exploitation in the projected algorithm.

$$
\begin{aligned}
& v_{i}^{k+1}=\omega * v_{i}^{k}+c_{1} \cdot r_{1} \cdot\left(x_{1}-x_{i}^{k}\right)+c_{2} \cdot r_{2} \cdot\left(x_{2}-x_{i}^{k}\right)+c_{3} \cdot r_{3} \cdot\left(x_{3}-x_{i}^{k}\right) \\
& x_{i}^{k+1}=x_{d}^{t+1}+v_{i}^{k+1} \\
& \omega=\left(\omega_{\max }-\omega_{\min }\right) \cdot \frac{\left(t_{\max }-t\right)}{t_{\max }}+\omega_{\min }
\end{aligned}
$$

Exploration and exploitation has been controlled by the inertia weight" $\omega "$;

$$
\begin{aligned}
& \overrightarrow{D_{\alpha}}=\left|\overrightarrow{C_{1}}, \overrightarrow{X_{\alpha}}-\omega * \vec{X}\right| \\
& \overrightarrow{D_{\beta}}=\left|\overrightarrow{C_{2}}, \overrightarrow{X_{\beta}}-\omega * \vec{X}\right| \\
& \overrightarrow{D_{\gamma}}=\left|\overrightarrow{C_{3}}, \overrightarrow{X_{\delta}}-\omega * \vec{X}\right|
\end{aligned}
$$


Initialization of parameters

$n$ " wolves positions are initialized arbitrarily $\in[1,0]$

$\alpha, \beta, \delta$ Solutions are attained by the fitness function value

Agent's fitness values are calculated by (35):

$$
\overrightarrow{D_{\alpha}}=\left|\overrightarrow{C_{1}}, \overrightarrow{X_{\alpha}}-\omega * \vec{X}\right| ; \overrightarrow{D_{\beta}}=\left|\overrightarrow{C_{2}}, \overrightarrow{X_{\beta}}-\omega * \vec{X}\right| ; \overrightarrow{D_{\gamma}}=\left|\overrightarrow{C_{3}}, \overrightarrow{X_{\delta}}-\omega * \vec{X}\right|
$$

while ( $\mathrm{t}<$ Maximum_iterations). For each population modernize the velocity by:

$$
v_{i}^{k+1}=\omega * v_{i}^{k}+c_{1} \cdot r_{1} \cdot\left(x_{1}-x_{i}^{k}\right)+c_{2} \cdot r_{2} \cdot\left(x_{2}-x_{i}^{k}\right)+c_{3} \cdot r_{3} \cdot\left(x_{3}-x_{i}^{k}\right)
$$

Modernize the agent's position into a binary position by:

$$
x_{i}^{k+1}=x_{d}^{t+1}+v_{i}^{k+1}
$$

End

Modernize A, $a$, $C$ and $w$

Through objective function assess all particles

Modernize the positions of $\alpha, \beta, \delta ; \mathrm{t}=\mathrm{t}+1$

End while

\section{SIMULATION RESULTS}

At first in standard IEEE 14 bus system [18] the validity of the proposed PWO algorithm has been tested. Table 1 shows the constraints of control variables. Table 2 shows the limits of reactive power generators, and comparison results are presented in Table 3.

Table 1. Constraints of control variables

\begin{tabular}{lcc}
\hline Variables & Minimum $(\mathrm{PU})$ & Maximum $(\mathrm{PU})$ \\
\hline Generator voltage & 0.95 & 1.1 \\
Transformer tap & 0.9 & 1.1 \\
VAR source & 0 & 0.20 \\
\hline
\end{tabular}

Table 2. Constrains of reactive power generators

\begin{tabular}{ccc}
\hline Variables & Q Minimum $(\mathrm{PU})$ & Q Maximum $(\mathrm{PU})$ \\
\hline 1 & 0 & 10 \\
2 & -40 & 50 \\
3 & 0 & 40 \\
6 & -6 & 24 \\
8 & -6 & 24 \\
\hline
\end{tabular}

Table 3. Simulation results of IEEE-14 system

\begin{tabular}{lcccccc}
\hline Control variables & Base case & MPSO [19] & PSO [19] & EP [19] & SARVA [19] & PWO \\
\hline Reduction in PLoss & 0 & 9.2 & 9.1 & 1.5 & 2.5 & 26.07 \\
Total PLoss (MW) & 13.550 & 12.293 & 12.315 & 13.346 & 13.216 & 10.1017 \\
\hline Note: NR*-Not reported & & & & & &
\end{tabular}

Then the proposed PWO algorithm has been tested in IEEE 30 bus system. Table 4 shows the constraints of control variables. Table 5 shows the limits of reactive power generators, and comparison results are presented in Table 6.

Table 4. Constraints of control variables

\begin{tabular}{lcc}
\hline Variables & Minimum $(\mathrm{PU})$ & Maximum $(\mathrm{PU})$ \\
\hline Generator voltage & 0.95 & 1.1 \\
Transformer tap & 0.9 & 1.1 \\
VAR source & 0 & 0.20 \\
\hline
\end{tabular}


Table 5. Constrains of reactive power generators

\begin{tabular}{ccc}
\hline Variables & Q Minimum $(\mathrm{PU})$ & Q Maximum $(\mathrm{PU})$ \\
\hline 1 & 0 & 10 \\
2 & -40 & 50 \\
5 & -40 & 40 \\
8 & -10 & 40 \\
11 & -6 & 24 \\
13 & -6 & 24 \\
\hline
\end{tabular}

Table 6. Simulation results of IEEE-30 system

\begin{tabular}{lcccccc}
\hline Control variables & Base case & MPSO [19] & PSO [19] & EP [19] & SARGA [19] & PWO \\
\hline Reduction in PLoss (\%) & 0 & 8.4 & 7.4 & 6.6 & 8.3 & 20.05 \\
Total PLoss (Mw) & 17.55 & 16.07 & 16.25 & 16.38 & 16.09 & 14.030 \\
\hline
\end{tabular}

Then the proposed PWO algorithm has been tested in IEEE 57 bus system. Table 7 shows the constraints of control variables, Table 8 shows the limits of reactive power generators and comparison results are presented in Table 9. Then the proposed PWO algorithm has been tested in IEEE 118 bus system. Table 10 shows the constraints of control variables and comparison results are presented in Table 11. Then IEEE 300 bus system [18] is used as test system to validate the performance of the proposed PWO algorithm. Table 12 shows the comparison of real power loss obtained after optimization.

Table 7. Constraints of control variables

\begin{tabular}{lcc}
\hline Variables & Minimum $(\mathrm{PU})$ & Maximum $(\mathrm{PU})$ \\
\hline Generator voltage & 0.95 & 1.1 \\
Transformer tap & 0.9 & 1.1 \\
VAR source & 0 & 0.20 \\
\hline
\end{tabular}

Table 8. Constrains of reactive power generators

\begin{tabular}{ccc}
\hline Variables & Q Minimum $(\mathrm{PU})$ & Q Maximum $(\mathrm{PU})$ \\
\hline 1 & -140 & 200 \\
2 & -17 & 50 \\
3 & -10 & 60 \\
6 & -8 & 25 \\
8 & -140 & 200 \\
9 & -3 & 9 \\
12 & -150 & 155 \\
\hline
\end{tabular}

Table 9. Simulation results of IEEE-57 system

\begin{tabular}{lcccccc}
\hline Control variables & Base case & MPSO [19] & PSO [19] & CGA [19] & AGA [19] & PWO \\
\hline Reduction in PLoss & 0 & 15.4 & 14.1 & 9.2 & 11.6 & 27.41 \\
Total PLoss (MW) & 27.8 & 23.51 & 23.86 & 25.24 & 24.56 & 20.179 \\
\hline
\end{tabular}

Note: NR*-Not reported.

Table 10. Constraints of control variables

\begin{tabular}{lcc}
\hline Variables & Minimum $(\mathrm{PU})$ & Maximum $(\mathrm{PU})$ \\
\hline Generator voltage & 0.95 & 1.1 \\
Transformer tap & 0.9 & 1.1 \\
VAR source & 0 & 0.20 \\
\hline
\end{tabular}

Table 11. Simulation results of IEEE-118 system

\begin{tabular}{lcccccc}
\hline Control variables & Base case & MPSO [19] & PSO [19] & PSO [19] & CLPSO [19] & PWO \\
\hline Reduction in PLoss & 0 & 11.7 & 10.1 & 0.6 & 1.3 & 13.86 \\
Total PLoss (MW) & 132.8 & 117.19 & 119.34 & 131.99 & 130.96 & 104.390 \\
\hline Note: NR*-Not reported. & & & &
\end{tabular}

Table 12. Comparison of real power loss

\begin{tabular}{ccccc}
\hline Parameter & Method CSA [20] & Method EGA [21] & Method EEA [21] & PWO \\
\hline PLOSS (MW) & 635.8942 & 646.2998 & 650.6027 & 613.1085 \\
\hline
\end{tabular}

Polar wolf optimization algorithm for solving optimal reactive power problem (Kanagasabai Lenin) 


\section{CONCLUSION}

In this paper PWO algorithm successfully solved the optimal reactive power problem. The hunting technique assists candidate solutions to trace the prey. Exploration and exploitation are balanced in iterations. Modernizing mechanism of wolves is function of three vectors position - $X_{1}, X_{2}, X_{3}$ which endorse every wolf to reach three most excellent solutions. For that the agents will work in a binary space. Proposed PWO algorithm has been tested in standard IEEE 14, 30, 57, 118, 300 bus test systems and simulation results show the projected algorithm reduced the real power loss. Percentage of real power loss reduction has been enhanced when compared to other reported algorithms.

\section{REFERENCES}

[1] K. Y. Lee, Y. M. Park and J. L. Ortiz, "Fuel-cost minimisation for both real-and reactive-power dispatches," IEE Proceedings C-Generation, Transmission and Distribution, vol. 131, no. 3, pp. 85-93, 1984.

[2] N. I. Deeb, "An efficient technique for reactive power dispatch using a revised linear programming approach," Electric Power System Research, vol. 15, no. 2, pp. 121-134, 1988.

[3] M. Bjelogrlic, M. S. Calovic, P. Ristanovic and B. S. Babic, "Application of Newton's optimal power flow in voltage/reactive power control," IEEE Transactions on Power Systems, vol. 5, no. 4, pp. 1447-1454, 1990.

[4] S. Granville, "Optimal reactive dispatch through interior point methods," IEEE Trans. on Power Systems, vol. 9, no. 1 , pp. 136-146, 1994.

[5] N. Grudinin, "Reactive power optimization using successive quadratic programming method," IEEE Transactions on Power Systems, vol. 13, no. 4, pp. 1219-1225, 1998.

[6] W. Yan, J. Yu, D. C. Yu and K. Bhattarai, "A new optimal reactive power flow model in rectangular form and its solution by predictor corrector primal dual interior point method," IEEE Trans. on Pow. Syst., vol. 21, no. 1, pp. 61-67, 2006.

[7] A. Mukherjee and V. Mukherjee, "Solution of optimal reactive power dispatch by chaotic krill herd algorithm," IET Generation, Transmission \& Distribution, vol. 9, no. 15, pp. 2351-2362, 2015.

[8] Z. Hu, X. Wang and G. Taylor, "Stochastic optimal reactive power dispatch: Formulation and solution method," Electr. Power Energy Syst., vol. 32, no. 6, pp. 615-621, 2010.

[9] M. A. P. Morgan, N. R. H. Abdullah, Mohd H. Sulaiman, M. Mustafa and R. Samad, "Multi-objective evolutionary programming (MOEP) using mutation based on adaptive mutation operator (AMO) applied for optimal reactive power dispatch," ARPN J. of Engineering and Applied Sciences, vol. 11, no. 14, pp. 8884-8888, 2016.

[10] K. Pandiarajan and C. K. Babulal, "Fuzzy harmony search algorithm based optimal power flow for power system security enhancement," International Journal Electric Power Energy Syst., vol. 78, pp. 72-79, 2016.

[11] M. Mahaletchumi, A. N. Hasma, M. H. Sulaiman, M. Mahfuzah and S. Rosdiyana, "Benchmark studies on optimal reactive power dispatch (ORPD) based multi-objective evolutionary programming (MOEP) using mutation based on adaptive mutation adapter (AMO) and polynomial mutation operator (PMO)," Journal of Electrical Systems, vol. 12, no. 1, pp. 121-132, 2016.

[12] R. Ng Shin Mei, Mohd H. Sulaiman and Z. Mustaffa, "Ant lion optimizer for optimal reactive power dispatch solution," Journal of Electrical Systems, Special Issue AMPE2015, pp. 68-74, 2016.

[13] A. Gagliano and F. Nocera, "Analysis of the performances of electric energy storage in residential applications," International Journal of Heat and Technology, vol. 35, special issue 1, pp. S41-S48, 2017.

[14] M. Caldera, P. Ungaro, G. Cammarata and G. Puglisi, "Survey-based analysis of the electrical energy demand in Italian households," Mathematical Modelling of Engineering Problems, vol. 5, no. 3, pp. 217-224, 2018

[15] E. Rashedi, S. Nezamabadi and S. Saryazdi, "GSA: A gravitational search algorithm," Information Sciences, vol. 179, no. 13, pp. 2232-2248, 2009.

[16] G-G. Wang, "Moth search algorithm: A bio-inspired metaheuristic algorithm for global optimization problems," Memetic Comp., vol. 10, pp. 151-164, 2016.

[17] L. Li, L. Sun, J. Guo, J. Qi, B. Xu and S. Li, "Modified discrete grey wolf optimizer algorithm for multilevel image thresholding," Computational Intelligence and Neuroscience, vol. 2017, pp. 1-16, 2017.

[18] IEEE, "The IEEE-test systems," 1993. [Online] Available at: http://www.ee.washington.edu/trsearch/pstca/.

[19] A. N. Hussain, A. A. Abdullah and O. M. Neda, "Modified particle swarm optimization for solution of reactive power dispatch," Research Journal of Applied Sciences, Engineering and Technology, vol. 15, no. 8, pp. 316-327, 2018.

[20] S. S. Reddy, "Optimal reactive power scheduling using cuckoo search algorithm," International Journal of Electrical and Computer Engineering, vol. 7, no. 5, pp. 2349-2356, 2017.

[21] S. S. Reddy, P. R. Bijwe and A. R. Abhyankar, "Faster evolutionary algorithm based optimal power flow using incremental variables," Electrical Power and Energy Systems, vol. 54, pp. 198-210, 2014.

\section{BIOGRAPHY OF AUTHOR}

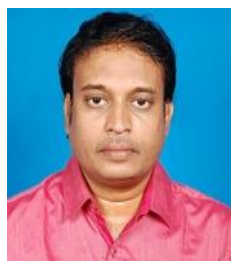

Kanagasabai Lenin has received his B.E., degree, electrical and electronics engineering from University of Madras, M.E., degree in power system from Annamalai University and completed $\mathrm{PhD}$ in electrical engineering from Jawaharlal Nehru Technological University Hyderabad, India. He published more than 275 international journal research papers and presently working as Professor in Prasad V. Potluri Siddhartha Institute of Technology, Kanuru, Vijayawada, Andhra Pradesh-520007. 